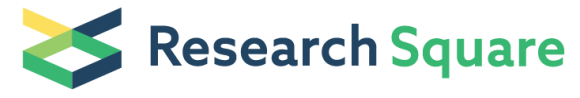

\section{Exploration of The Lower Threshold of lodine Intake In Southern Chinese Young Adults Based On 'Overflow Theory' In An lodine Balance Study}

\section{Jun Wang}

Shenzhen Center for Chronic Disease Control https://orcid.org/0000-0001-5808-7135

\section{Hongmin Zhang}

Shenzhen Center for Chronic Disease Control

\section{Deqian Mao}

Chinese Center for Disease Control and Prevention National Institute for Nutrition and Health

\section{Hongxing Tan}

Shenzshen Center for Chronic Disease Control

\section{Wei Yu}

Shenzhen Center for Chronic Disease Control

\section{Jian Xu}

Shenzhen Center for Chronic Disease Control

\section{Wenxu Hong}

Shenzhen Center for Chronic Disease Control

\section{Jianhua Piao}

Chinese Center for Disease Control and Prevention National Institute for Nutrition and Health

\section{Lichen Yang}

Chinese Center for Disease Control and Prevention National Institute for Nutrition and Health

\section{Xiaobing Liu}

Chinese Center for Disease Control and Prevention National Institute for Nutrition and Health

\section{Jiaxi Lu}

Chinese Center for Disease Control and Prevention National Institute for Nutrition and Health

\section{Weidong Li}

Chinese Center for Disease Control and Prevention National Institute for Nutrition and Health

\section{Yajie Li}

Chinese Center for Disease Control and Prevention National Institute for Nutrition and Health

Xiaoli Liu

Shenzhen Center for Chronic Disease Control

\section{Xiaoguang Yang ( $\nabla$ xgyangcdc@163.com )}

Chinese Center for Disease Control and Prevention National Institute for Nutrition and Health 
Research

Keywords: lodine, lodine overflow, Chinese adults, Balance experiment, Euthyroid

Posted Date: August 31st, 2021

DOl: https://doi.org/10.21203/rs.3.rs-824291/v1

License: (c) (i) This work is licensed under a Creative Commons Attribution 4.0 International License. Read Full License 


\section{Abstract}

Background: Appropriate iodine intake for adults is essential to reduce the prevalence of thyroid diseases, but there is little research data on iodine requirement of Chinese population. This study aimed to explore the iodine requirement of young adults to maintain a healthy status based on 'overflow theory'.

Methods: lodine-balance experiment has been performed in this project. We conducted an 18-day study consisted of a 6-day acclimation period and 3 consecutive experimental stages in 37 Chinese healthy young adults ( 23 female and 14 male). Each stage was consumed for 4 days. Strictly-controlled low-iodine intake diets were provided for adults in the first period, an egg or $125 \mathrm{~mL}$ milk was added in the second and third period, respectively. The dietary samples, 24-h urine specimens and faeces of volunteers were collected daily for assessment of iodine intake and excretion in volunteers.

Results: Mean values of iodine intake $(22.7 \pm 3.6,35.1 \pm 3.7$, and $52.2 \pm 3.8 \mu \mathrm{g} / \mathrm{d})$, excretion $(64.7 \pm 13.9$, $62.3 \pm 12.6$, and $94.3 \pm 14.5 \mu \mathrm{g} / \mathrm{d})$ and iodine balance $(-35.2 \pm 19.5,-21.0 \pm 19.8$, and $-33.5 \pm 26.9 \mu \mathrm{g} / \mathrm{d})$ were significantly different among three periods for male ( $P<0.001$ for all); mean values of iodine intake $(16.6 \pm 3.1,29.7 \pm 2.7$, and $48.0 \pm 2.7 \mu \mathrm{g} / \mathrm{d})$, and excretion $(47.0 \pm 9.9,55.5 \pm 8.1$, and $75.7 \pm 12.4 \mu \mathrm{g} / \mathrm{d})$ were significantly different among three periods for female $(P<0.001$ for all). No significant difference was observed among the 3 periods for female in the iodine balance $(-30.5 \pm 9.3,-25.9 \pm 7.3$, and $-27.6 \pm 12.1 \mu \mathrm{g} / \mathrm{d})$. The linear regression equation of iodine excretion on iodine intake was $Y=0.979 X+37.04$ (male) and $Y=0.895 X+31.48$ (female). Compared with stage 2, iodine excretion increments in stage 3 had exceeded the iodine intake increment for men. The ratio of increment was 1.675 for male when the average iodine intake was $52.2 \mu \mathrm{g} / \mathrm{d}$ in stage 3 . When the iodine excretion increment equaled to the iodine intake increment, the daily iodine intake of men was $47.0 \mu \mathrm{g}$.

Conclusion: We have evaluated the iodine requirement of young adults in southern China based on overflow theory. Our results indicate the lower limit of iodine requirement for Chinese young men is $47.0 \mu \mathrm{g} / \mathrm{d}$. The trial was registered at www.chictr.org.cn as ChiCTR1800014877.

\section{Background}

lodine is one of the essential trace elements for the human body. It plays an important role in the synthesis of thyroid hormone and has been regarded as a determinant of thyroid disorders ${ }^{[1]}$. Long-term iodine insufficiency intake is a risk factor for nodules, subclinical hypothyroidism and thyroid goitre ${ }^{[2-3]}$. Since universal salt iodization (USI) was implemented in 1995, China has made remarkable achievements in the prevention and control of iodine deficiency disorders (IDD). By 2000, China had basically reached the level of national IDD eliminating and according to the results of 'twelfth-five' Plan of National Endemic Disease Control, $94.2 \%$ of counties had achieved the goal of IDD eliminating at the end of $2015^{[4]}$. However, several recent studies reported that excessive iodine intake may associated with high thyroid volume for children and hypothyroidism for adults ${ }^{[5-7]}$. There is a U-shaped relationship between iodine intake and thyroid disorders in adults ${ }^{[8]}$. According to the National Central Cancer of China, the incidence of thyroid cancer had increased from 3.5 per 100,000 in 2004 to 8.8 per 100,000 in 2012 and annual growth rate was $16.8 \%$ 
[9]. Currently, along with the increasing of thyroid disease, the relationship between iodine excess and USI has caused more concern. A report from China National Expert Committee on Food Safety Risk Assessment showed that the iodine nutritional status of Chinese residents is generally at an appropriate and safe level in $2010^{[10]}$. Considering these factors, national iodized salt standard was revised from $35 \mathrm{mg} / \mathrm{kg}$ to $20 \sim 30$ $\mathrm{mg} / \mathrm{kg}$ in March 2012, resulting average iodine content in edible salt decreased from $30.7 \mathrm{mg} / \mathrm{kg}$ in 2005 to $24.3 \mathrm{mg} / \mathrm{kg}$ in $2014^{[11]}$. The new iodized salt criterion inevitably has an impact on the total dietary iodine intake of Chinese. Therefore, a reasonable iodine dietary reference intake should be established to ensure public health.

There are obvious regional differences in dietary iodine reference intake throughout the world. The United States and Canada set the iodine estimated average requirement (EAR) of $95 \mu \mathrm{g} / \mathrm{d}$ for adults using data published in the 1960s on thyroid iodine metabolism, turnover and balance studies ${ }^{[12-14]}$. Because of the lack of experimental data on Chinese population, Chinese Nutrition Society determined the EAR for iodine as $85 \mu \mathrm{g} / \mathrm{d}$ considering the difference in body weight between adult Chinese population and Western population ${ }^{[15]}$. In addition, with the implementation of USI, the iodine nutritional status of the populations in the world has undergone tremendous changes, and thus thyroid iodine content and turnover in euthyroid subjects recently are different from that in the middle of last century. Therefore, the iodine requirement based on the results of previous studies has been difficult to adapt to the change of iodine requirement under the new global iodine nutrition background.

Metabolic balance study is a classical method to determine nutrient requirements by assessing the relationship between total nutrient intake and excretion ${ }^{[16]}$. For iodine-sufficient adults, the iodine balance should be zero balance for a while, that is, total iodine intake and excretion are basically equal. Under normal conditions, about $90 \%$ of the iodine in the human body is excreted through the urine, and about $10 \%$ of the iodine is excreted through the feces, then the iodine excretion through the urine and feces can represent the total iodine excretion ${ }^{[4]}$. However, there are very few iodine balance studies have been reported in China due to the difficulty in controlling dietary iodine intake and the difficulty in collecting complete 24 hour urine over a period of time ${ }^{[17]}$.

Based on the balance study theory and iodine nutritional status of Shenzhen adults, the 'iodine overflow' theory has been applied ${ }^{[29]}$, that is:1) healthy adults can absolutely and effectively utilize iodine, and when the iodine intake is sufficient for the body's metabolic needs and necessary storage, the excess iodine will be excreted; 2) iodine excretion increases with the increase of iodine intake and when iodine intake exceeds a certain threshold, the increased dietary iodine intake will be completely excreted, this threshold should be the low limit of iodine dietary reference intake for adults. The aim of present study was to determine the critical value at which the increased dietary iodine intake was substantially excreted through urine and feces. It should be the low limit of iodine dietary reference intake for Chinese young adults.

\section{Methods}


We recruited 39 volunteers aged $18 \sim 23$ years old from Shenzhen Polytechnic in 2018. The weight and height of the volunteers were measured by calibrated instruments to calculate body mass index (BMI). All the subjects were given unified physical examinations in professional hospital before and after dietary interventions. Overnight ( $\geq 8$ hour) fasting blood specimens were collected from each participant for measurement of thyroid hormones, inflammatory, liver and kidney function indicators. Volunteers were included in our study if they fulfilled the following criteria:1) no thyroid disorders and treatment history; 2) no exposure to iodine-containing dietary supplement or iodine-containing medication; 3 ) normal urinary iodine concentration; 4) no functional constipation or diarrhea.

This trial was registered in the Chinese Clinical Trial Registry (ChiCTR1800014877). All procedures involving human participants were approved by the Ethical Committee of the Chinese Center for Disease Control and Prevention. All subjects provided their written informed consent prior to participation.

\section{Study design}

Considering the potential effect of female physiological period, the whole study was executed limited to a total duration of 18 days, which was divided into acclimation period and three low-iodine intake stages. The project took place in late spring and early summer (March and April) in the southern Chinese metropolis of Shenzhen, with ambient temperatures around 20 degrees. The subjects were required to avoid intensive physical activities during the whole study for controlling iodine excretion from sweat. Diet plans were carefully designed based on balanced meals avoiding from iodine-rich foods and condiments (i.e., kelp, seaweed, iodized salt, etc.). Serving foods and drinking water were restrictively monitored and provide to all the participants. Acclimation period was 6 days before the beginning of the studies in order to reducing the effect of stored iodine in the thyroid (Fig. 1). Subsequently, there were three low-iodine diet (LID) stages, each lasting 4 days (12 days total). In stage 2 and 3, a hard-boiled egg (approx. 50g each) or $125 \mathrm{~mL}$ of milk was used for intervention, respectively. The dietary samples, 24-h urine specimens and faeces of volunteers were collected daily by our investigators.

\section{Diet design, preparation and processing}

According to the basic data of the typical dietary pattern obtained from the school canteen and market supply, a 12-day recipe met the principles of nutrient balance was designed by nutritionists. Daily recipe contained staple food, vegetables, fruits, beans and meat, but seaweed and kelp were prohibited. Before food processing, the iodine contents of all cooked foods, including raw materials, compound condiments, snacks and drinking water, were carefully determined. Diets contained different levels of iodine in different periods. All diet cooked with non-iodized salt by the canteen staff. Six drinking water samples collected in school have been detected, and the mean water iodine was $11.8 \mu \mathrm{g} / \mathrm{L}$. To avoid the bias of iodine content in different drinks, commercially available pure water in the supermarket was used to cook food and drink for subjects. To avoid the bias of iodine content in different drinks, pure water was used to cook food and drink for subjects. The 12-day recipe used in this study was shown in Supplemental table 1.

\section{Sample collection}


Participants were provided with a plastic beaker (1L) and two plastic bags with sealed lid (5L), and they were guided and demonstrated how to collect the 24-h urine by staff. The 24-h urine was collected for 12 consecutive days from 7 am on the first day to 7 am on the 13th day of the trial. Upon completion of the 24$\mathrm{h}$ collection, the urine volume of each participant was measured and four aliquots were frozen at $-20^{\circ} \mathrm{C}$ for later analysis.

Carmine capsule was administered to all subjects before breakfast to mark feces on the first day, fifth day, ninth day and the thirteenth day respectively. Fecal specimens of each subject were collected according to the labeled red pigmentation at each stage. Once the feces of each stage were completely collected, they were weighed, homogenized, proportionally taken a portion for about $200 \mathrm{~g}$ and pressed using moulding followed by lyophilization and freezing at $-20^{\circ} \mathrm{C}$.

During the study, all the diet offered to the subjects was cooked by the university canteen according to the recipe. Trained staff weighed the food supplied for the subjects before and after each meal to access actual intake. A duplicate dietary sample for each meal was collected and homogenized in one hour, and then stored in the refrigerator at $-20^{\circ} \mathrm{C}$ before detection.

\section{Laboratory analysis}

Quantitative rapid test kits (Conson Biochemicals, China) were used to detect 24-hour urinary iodine concentration every day to prevent iodine intake other than the diet we provided. lodine content in food ${ }^{[18]}$, urine ${ }^{[19]}$ and faeces ${ }^{[18]}$ were determined using arsenic-cerium catalytic spectrophotometry at National lodine Deficiency Disease Reference Laboratory in Beijing. The serum thyrotropin (TSH), free thyroxin (FT4) and free triiodothyronine (FT3) were measured in all participants by an automated chemiluminescence immunoassay analyzer (Bayer ADVIA Cetaur System, Bayer Healthcare, Germany).

\section{Quality Control}

Multiple quality control (QC) measures were introduced to guarantee the reliability of the study findings. Prior to the beginning of the survey, all the investigators were trained uniformly for recording weighed food by the principal investigator from National Institute for Nutrition and Health of Chinese CDC. Double entry data have been used to ensure accuracy and completeness. One of the difficulties and limitations in the study was the 24 -hour urine samples collection. The total urine volume and 24 -hour urinary creatinine excretion were applied to validate the completeness of the 24-hour collection sample. Eating out or consuming food not provided by the project team, was prohibited. The iodine concentrations of 24-hour urine samples were determined promptly every day, and 24-hour urine iodine excretion was calculated to monitor volunteers' dietary iodine intake. Carmine red, a biologically inert substance that was rapidly excreted in faeces, was administered to all participants at the beginnings and ends of each stage to distinguish different stages of stool samples.

\section{Statistical analysis}

Data were analyzed using Excel and IBM SPSS 21.0 Statistics software. The normal distribution data were expressed as mean \pm SD. Differences among the 3 periods were analyzed by one-way repeated measures 
ANOVA and by the use of Bonferroni correction for multiple comparisons. A $P$ value $<0.05$ was considered as statistically significant.

\section{'lodine overflow' hypothesis}

'Iodine overflow' hypothesis ${ }^{[29]}$ was first proposed by our group in 2020, which was appropriate for exploring the recommended nutrient intake of iodine under saturation state. Shenzhen, as a coastal city, has implemented USI policy over twenty years and the iodine nutrition status of its residents is appropriate. Therefore, dietary iodine was adequate to meet needs for thyroid hormone synthesis and required storage, while the remaining iodine maybe excreted by 'overflow'. As we know, iodine excretion increases with iodine intake in certain extent. Dietary contained 3 concentrations of iodine was successively provided for all subjects in 3 periods. Data of iodine excretion increment and intake increment were obtained using the change of iodine intake and excretion between different periods. Ratio was calculated by the iodine excretion increment to iodine intake increment. A scatter diagram was plotted by ratio vs iodine intake, and then the iodine intake was calculated when ratio equaled to 1 with linear regression method.

\section{Results}

\section{Characteristic of study population}

Of the 39 young healthy adults recruited, 37 ( 23 female and 14 male) successfully completed this study were included. The mean age of the subjects was $20.1 \pm 1.0$ years, which ranged from 18 to 23 years. Median urinary iodine concentration (UIC) at screening was 121.5 (90.9-181.8) $\mu \mathrm{g} / \mathrm{L}$ and 126.4 (73.9-161.9) $\mu \mathrm{g} / \mathrm{L}$ for male and female, respectively. After adaptation period, the UIC was $31.5(25.6-43.3) \mu \mathrm{g} / \mathrm{L}$ for male and $20.0(15.2-31.7) \mu \mathrm{g} / \mathrm{L}$ for female.

The level of TSH, FT4 and FT3 were all within the normal reference value (Table 1). The measured mean \pm SD serum TSH, FT4 and FT3 of male before trial $(1.98 \pm 0.72 \mu \mathrm{lU} / \mathrm{ml}, 19.62 \pm 2.48 \mathrm{pmol} / \mathrm{L}$ and $5.67 \pm 0.45$ $\mathrm{pmol} / \mathrm{L})$ had no significant difference compared with the values from after trial $(2.02 \pm 0.84 \mu \mathrm{lU} / \mathrm{ml}, 20.54 \pm$ $2.23 \mathrm{pmol} / \mathrm{L}$ and $5.61 \pm 0.53 \mathrm{pmol} / \mathrm{L}, P>0.05$ ). Similar results were seen in female. 
Table 1

Comparison of thyroid function parameters before and after trial (mean $\pm \mathrm{SD}$ )

\begin{tabular}{|c|c|c|c|}
\hline & FT4 (pmol/L) & FT3 (pmol/L) & TSH $(\mu l \mathrm{U} / \mathrm{ml})$ \\
\hline \multicolumn{4}{|c|}{ Male $(n=14)$} \\
\hline Before trial & $19.62 \pm 2.48$ & $5.67 \pm 0.45$ & $1.98 \pm 0.72$ \\
\hline After trial & $20.54 \pm 2.23$ & $5.61 \pm 0.53$ & $2.02 \pm 0.84$ \\
\hline$P$ value & 0.167 & 0.744 & 0.904 \\
\hline \multicolumn{4}{|c|}{ Female $(n=23)$} \\
\hline Before trial & $17.74 \pm 2.09$ & $4.92 \pm 0.6$ & $1.86 \pm 0.91$ \\
\hline After trial & $17.44 \pm 2.15$ & $4.92 \pm 0.59$ & $1.72 \pm 0.94$ \\
\hline$P$ value & 0.330 & 0.970 & 0.079 \\
\hline \multicolumn{4}{|l|}{ All $(n=37)$} \\
\hline Before trial & $18.45 \pm 2.4$ & $5.2 \pm 0.65$ & $1.91 \pm 0.83$ \\
\hline After trial & $18.61 \pm 2.64$ & $5.18 \pm 0.65$ & $1.83 \pm 0.89$ \\
\hline$P$ value & 0.604 & 0.797 & 0.147 \\
\hline \multicolumn{4}{|c|}{ FT4, free thyroxine; FT3, free triiodothyronine; TSH, thyroid stimulating hormor } \\
\hline
\end{tabular}

The values of iodine intake, iodine excretion and iodine balance of 37 volunteers at different iodine doses are shown in Table 2. A total of 359 samples were analyzed in this study, while others were excluded because their urine collection were not complete. Significant differences in total iodine intake were found among all 3 doses for both males and females ( $P<0.001$ for all comparisons). Among different iodine intake statuses, iodine excretion differed in both of the genders $(P<0.001)$. There were no significant differences in iodine retention among the 3 periods for female $(P=0.262)$. 
Table 2

Summary of daily iodine intake, iodine excretion, and iodine retention for the subjects (mean \pm SD)

\begin{tabular}{|c|c|c|c|c|}
\hline & Stage 1 & Stage 2 & Stage 3 & $P^{c}$ \\
\hline \multicolumn{5}{|l|}{ Male $(n=14)$} \\
\hline Total iodine intake, $\mu \mathrm{g} / \mathrm{d}$ & $22.7 \pm 3.6$ & $35.1 \pm 3.7^{\mathrm{a}}$ & $52.2 \pm 3.8^{\mathrm{ab}}$ & $<0.001$ \\
\hline Urine iodine, $\mu \mathrm{g} / \mathrm{d}$ & $56.4 \pm 13.2$ & $51.4 \pm 11.5^{\mathrm{a}}$ & $78.9 \pm 15.4 \mathrm{ab}$ & $<0.001$ \\
\hline Feces iodine, $\mu \mathrm{g} / \mathrm{d}$ & $9.1 \pm 4.0$ & $11.9 \pm 3.4$ & $16.7 \pm 5.8^{\mathrm{a}}$ & $<0.001$ \\
\hline Total iodine excretion, $\mu \mathrm{g} / \mathrm{d}$ & $64.7 \pm 13.9$ & $62.3 \pm 12.6$ & $94.3 \pm 14.5^{\mathrm{ab}}$ & $<0.001$ \\
\hline lodine balance, $\mu \mathrm{g} / \mathrm{d}$ & $-35.2 \pm 19.5$ & $-21.0 \pm 19.8^{a}$ & $-33.5 \pm 26.9^{b}$ & $<0.001$ \\
\hline \multicolumn{5}{|l|}{ Female $(\mathrm{n}=23)$} \\
\hline Total iodine intake, $\mu \mathrm{g} / \mathrm{d}$ & $16.6 \pm 3.1$ & $29.7 \pm 2.7^{\mathrm{a}}$ & $48.0 \pm 2.7^{a b}$ & $<0.001$ \\
\hline Urine iodine, $\mu \mathrm{g} / \mathrm{d}$ & $40.8 \pm 9.5$ & $47.8 \pm 8.1^{\mathrm{a}}$ & $66.4 \pm 11.0^{\mathrm{ab}}$ & $<0.001$ \\
\hline Feces iodine, $\mu \mathrm{g} / \mathrm{d}$ & $6.2 \pm 1.6$ & $8.0 \pm 3.1$ & $9.7 \pm 6.5^{\mathrm{a}}$ & 0.044 \\
\hline Total iodine excretion, $\mu \mathrm{g} / \mathrm{d}$ & $47.0 \pm 9.9$ & $55.5 \pm 8.1^{\mathrm{a}}$ & $75.7 \pm 12.4^{\mathrm{ab}}$ & $<0.001$ \\
\hline lodine balance, $\mu \mathrm{g} / \mathrm{d}$ & $-30.5 \pm 9.3$ & $-25.9 \pm 7.3$ & $-27.6 \pm 12.1$ & 0.262 \\
\hline \multicolumn{5}{|l|}{ Total $(n=37)$} \\
\hline Total iodine intake, $\mu \mathrm{g} / \mathrm{d}$ & $18.9 \pm 4.4$ & $31.7 \pm 4.1^{\mathrm{a}}$ & $49.6 \pm 3.7^{a b}$ & $<0.001$ \\
\hline Urine iodine, $\mu \mathrm{g} / \mathrm{d}$ & $46.7 \pm 13.3$ & $49.2 \pm 9.6$ & $71.1 \pm 14.0^{\mathrm{ab}}$ & $<0.001$ \\
\hline Feces iodine, $\mu \mathrm{g} / \mathrm{d}$ & $7.3 \pm 3.1$ & $9.5 \pm 3.7^{\mathrm{a}}$ & $12.3 \pm 7.1^{\mathrm{a}}$ & $<0.001$ \\
\hline Total iodine excretion, $\mu \mathrm{g} / \mathrm{d}$ & $53.7 \pm 14.3$ & $58.1 \pm 10.4^{a}$ & $82.7 \pm 15.9$ ab & $<0.001$ \\
\hline lodine balance, $\mu \mathrm{g} / \mathrm{d}$ & $-32.3 \pm 14.0$ & $-24.1 \pm 13.4^{\mathrm{a}}$ & $-29.8 \pm 18.9$ & 0.003 \\
\hline
\end{tabular}

Figure 2 displayed the relationship between iodine excretion and iodine intake for male (Fig. 2A), female (Fig. 2B) and all subjects (Fig. 2C), respectively. The regression equations were $\mathrm{Y}=0.979 \mathrm{X}+37.04$ (male) and $Y=0.895 X+31.48$ (female). The intercepts $37.04 \mu \mathrm{g} / \mathrm{d}$ and $31.48 \mu \mathrm{g} / \mathrm{d}$ represented an indispensable iodine excretion, which were equally different from zero $(P<0.001)$. 
lodine excretion increment increased with increasing iodine intake increment as shown in Table 3. Compared with stage 1 , the average daily iodine intake for male increased $12.4 \mu \mathrm{g}$ in stage 2 , while the average daily iodine excretion decreased $3.2 \mu \mathrm{g}$, and the ratio was -0.324 . Furthermore, the average iodine intake in stage 3 was $17.7 \mu \mathrm{g} / \mathrm{d}$ more than stage 2, while the average iodine excretion increment was $29.3 \mu \mathrm{g} / \mathrm{d}$. The ratio of increment was $1.675 \mathrm{for}$ male when the average iodine intake was $52.2 \mu \mathrm{g} / \mathrm{d}$ in stage 3. It represented that the increment of iodine intake was all excreted.

Table 3

Changes in the ratio of iodine intake to excretion increment $(\mu \mathrm{g} / \mathrm{d})$

\begin{tabular}{|c|c|c|c|c|c|c|}
\hline \multirow[t]{2}{*}{ Variables } & \multicolumn{3}{|c|}{ period2( $\triangle$ increment) } & \multicolumn{3}{|c|}{ period3( $\triangle$ increment) } \\
\hline & $\Delta_{\text {increment }_{\text {in }}}{ }^{a}$ & $\Delta^{\text {increment }}{ }_{e x}^{\text {b }}$ & ratioc & $\Delta^{\text {increment }_{\text {in }}}{ }^{\mathrm{a}}$ & $\Delta^{\text {increment }}{ }_{e x}^{\text {b }}$ & ratio $^{c}$ \\
\hline Male & 12.4 & -3.2 & -0.324 & 17.7 & 29.3 & 1.675 \\
\hline Female & 13.0 & 9.2 & 0.699 & 18.5 & 19.0 & 1.034 \\
\hline Total & 12.8 & 4.3 & 0.293 & 18.2 & 22.9 & 1.276 \\
\hline \multicolumn{7}{|c|}{$\begin{array}{l}{ }^{\text {a }} \triangle \text { increment }_{\text {in }} \text { was calculated using the iodine intake of latter stage minus the previous stage; } \\
\triangle \text { increment }_{\text {ex }} \text { was calculated using the iodine excretion of latter stage minus the stage period } ; \text { ratio = } \\
\triangle \text { increment }_{e x} / \triangle \text { increment }_{\text {in }}\end{array}$} \\
\hline
\end{tabular}

There was a significantly positive correlation between iodine increment ratio (ratio $=\triangle$ increment $_{\mathrm{ex}} /$ $\triangle$ increment $\left._{\text {in }}\right)$ and iodine intake for male $(r=0.64, P<0.001)$, but not for female $(r=0.14, P=0.09)$. Figure 3 showed linear relationship between iodine increment ratio and iodine intake, the equations of the leastsquares line were $Y=0.095 X-3.463$ for male, and $Y=0.014 X+0.324$ for female. The intercept $(-3.463)$ and the slope $(0.095)$ of male were significantly different from zero $(p<0.001)$. When the ratio was equal to 1 , that was, the increment in daily iodine excretion was equal to the increment in daily iodine intake, the minimum iodine requirement of male was achieved at an iodine intake of $47.0 \mu \mathrm{g} / \mathrm{d}$.

\section{Discussion}

Mean iodine intake of all subjects in 3 periods was $18.9 \pm 4.4,31.7 \pm 4.1$ and $49.6 \pm 3.7 \mu \mathrm{g} / \mathrm{d}$, respectively. The results showed that iodine intake of young adults was consistently lower than $60 \mu \mathrm{g} / \mathrm{d}$ in three periods, which was considerably lower than $120 \mu \mathrm{g} / \mathrm{d}$ recommended by Chinese Nutrition Society ${ }^{[15]}$. As almost all subjects were in negative iodine balance during the study, and balance study cannot define iodine requirement, we use 'iodine overflow' method to evaluate the lower threshold of iodine requirement of young adults. We observed that the ratio of iodine excretion increment and iodine intake increment increasing with the iodine intake. When the ratio equaled one, value of iodine intake $47.0 \mu \mathrm{g} / \mathrm{d}$ was considered as the lower threshold of daily iodine intake in Chinese young male adults.

In our opinion, the negative iodine balance might be related to the iodine status of the subjects who were in an 'over-saturated state'. First of all, Shenzhen as a coastal city located in southern China has been reached 
the standard of eliminating IDD many years ago. Andersson ${ }^{[20]}$ considered that the iodine stored in the thyroid gland of population is sufficient to ensure adequate hormone synthesis and secretion where USI has been effective for at least 2 years. Secondly, the 37 young adults who lived in Shenzhen at least 2 years were in an adequate nutritional iodine status before entering our study with UIC $126.4 \mu \mathrm{g} / \mathrm{L}$ defined by the WHO standard ${ }^{[21]}$. We also observed urine iodine excretion increased with iodine intake although UIC was below $100 \mu \mathrm{g} / \mathrm{L}$ (iodine deficiency according to WHO) during the study. However, a recent study suggested that Chinese pregnant women with UIC of $107.4 \mu \mathrm{g} / \mathrm{L}$ (less than the WHO's $150 \mu \mathrm{g} / \mathrm{L}$ criterion) maintained thyroid function in both themselves and their newborn babies ${ }^{[22]}$. Last but not least, thyroid function was detected to evaluate iodine status of subjects with low intakes (from 18.9 to $49.6 \mu \mathrm{g} / \mathrm{d}$ ) in our study. TSH, FT4 and FT3 were not only within the normal range but also had no difference before and after this study.

The balance study was usually used to determine iodine EAR of population by assessing the total iodine intake and excretion ${ }^{[17,23]}$. From the perspective of balance study, the results of our study were consistent with previously reported findings of negative iodine balance in healthy subjects ${ }^{[24-26]}$. Malvaux ${ }^{[24]}$ found the healthy children and adolescents were in negative balance on low iodine intake of $32 \mu \mathrm{g} / \mathrm{d}$, similar to the iodine intake in stage 2 of our study $(31.6 \mu \mathrm{g} / \mathrm{d})$. One may argue that the low iodine intake lead to the negative iodine balance. A balance study conducted by Vought ${ }^{[27]}$ demonstrated that all of the healthy euthyroid volunteers were in negative balance even though they were fed with 3 levels of iodine intake ranging from 65.8 to $450.4 \mu \mathrm{g} / \mathrm{d}$ in random order. Nevertheless, it is impossible for healthy adults to maintain 'negative iodine balance' constantly, and the classical iodine balance experiment cannot reasonably explain this phenomenon.

Considering that the EAR cannot be calculated from our data, the method of iodine spillage was used to determine the lower limit of iodine requirement for young adults. It does not require the population to reach zero iodine balance, which to some extent makes up for the defect that the iodine balance method cannot evaluate the iodine requirement in the case of negative iodine balance. DeGroot ${ }^{[14]}$ had estimated the thyroid absolute iodide uptake in four normal thyroid function subjects by using radioactive ${ }^{131}$ I. The results showed that the mean of absolute iodine uptake was $54 \mu \mathrm{g} / \mathrm{d}$ by the method of Riggs ${ }^{[28]}$, close to lower limit of iodine requirement of men in our study $(47.0 \mu \mathrm{g} / \mathrm{d})$. Nevertheless, considering ethical issues, it is currently impossible to conduct human trials using radioisotope labeling methods. Therefore, our 'iodine overflow' hypothesis may open up a new way for establishing the dietary reference intake of iodine for healthy adults even if they are in negative iodine balance.

Our present study has several limitations. First, a major limitation of this study is the narrower ranges of iodine exposure $(18.9 \mu \mathrm{g} / \mathrm{d}$ to $49.6 \mu \mathrm{g} / \mathrm{d})$ compared with previous reports, and thus contributes no information as to the effect of high iodine intakes on iodine balance. However, multiple iodine intake levels were designed at narrow range may improve the accuracy of lower threshold results. Second, it may also be objected that the total iodine excretion is underestimated because iodine losses from sweat, skin and menstruation are not measured. This study was conducted in the spring and volunteers were required to avoid high-intensity physical activity during the test to reduce sweating. Third, in order to avoid the effect of menstruation on iodine excretion and to maintain the compliance of subjects, we avoided the menstrual

Page $11 / 15$ 
period and caused a relatively short experimental period. Long term influence of such iodine intake level on thyroid function remains to be determined.

\section{Conclusions}

In conclusion, to the best of our knowledge, this is the first research to determine the iodine requirement for southern Chinese adults based on 'iodine overflow' hypothesis. We found that the iodine requirement for healthy Chinese young men was less than current EAR. Further researches are needed to verify our results in a wider ranges of iodine exposure and pay more attention to the iodine status and health of women.

\section{Abbreviations}

USI: universal salt iodization, EAR: estimated average requirement, TSH: serum thyrotropin, FT4: free thyroxin, FT3: free triiodothyronine, UIC: urinary iodine concentration, LID: low-iodine diet.

\section{Declarations}

\section{Acknowledgements}

We thank all the participants and the staff in our study, and especially thank Professor Liu Dong and Sun Shixin of Shenzhen Polytechnic for help with organizing, recruiting and sample collection.

\section{Authors' contributions}

The authors' responsibilities were as follows- JW, DM, $X L$, and $X Y$ designed the research; $D M, H Z, H T, X L$, $J L, W L, Y L, J P$, and $L Y$ conducted the research; $H Z, H T$, and WY: analyzed data; JW, HZ: wrote the manuscript; JX, WH, JP, and $X Y$ supervised the study; $X L$ and $X Y$ had primary responsibility for final content; and all authors: read and approved the final manuscript. None of the authors declared a competing interest.

\section{Funding}

Supported by the National Natural Science Foundation of China (81872624) and the Sanming Project of Medicine in Shenzhen (SZSM201611017).

\section{Availability of data and materials}

All relevant data are included in this manuscript.

\section{Ethics approval and consent to participate}

The study protocol was approved by the ethics committee of Shenzhen Center for Chronic Disease Control (SZCCC-201802). Consent to participate was obtained from each participant in written form. 
All authors consent to this manuscript's publication.

\section{Competing interests}

The authors declare that they have no competing interests.

\section{References}

1. Zimmermann MB, Boelaert K. lodine deficiency and thyroid disorders. Lancet Diabetes Endocrinol. 2015;3(4):286-95.

2. Taylor PN, Albrecht D, Scholz A, et al. Global epidemiology of hyperthyroidism and hypothyroidism. Nat Rev Endocrinol. 2018;14(5):301-16.

3. Dumont JE, Ermans AM, Maenhaut C, et al. Large goitre as a maladaptation to iodine deficiency. Clin Endocrinol (Oxf).1995,43:1-10.

4. Chinese Society of endemiology/Chinese Nutrition Society/Chinese Society of Endocrinology. lodine supplementation guidelines for Chinese residents. Beijing: People's Medical Publishing House; 2018.

5. Zimmermann MB, Ito Y, Hess SY, et al. High thyroid volume in children with excess dietary iodine intakes. Am J Clin Nutr. 2005;81(4):840-4.

6. Chen W, Li X, Wu Y, et al. Associations between iodine intake, thyroid volume, and goiter rate in schoolaged Chinese children from areas with high iodine drinking water concentrations. Am J Clin Nutr. 2017;105(1):228-33.

7. Laurberg P, Cerqueira $C$, Ovesen $L$, et al. lodine intake as a determinant of thyroid disorders in populations. Best Pract Res Clin Endocrinol Metab. 2010;24(1):13-27.

8. Wang B, He W, Li Q, et al. U-shaped relationship between iodine status and thyroid autoimmunity risk in adults. Eur J Endocrinol. 2019;181:255-66.

9. Chen W, Zheng R, Baade PD, et al. Cancer statistics in China, 2015. CA Cancer J Clin. 2016;66(2):11532.

10. China National Expert Committee on Food Safety Risk Assessment. Salt iodization and risk assessment of iodine status in Chinese population, 2010.

11. Ministry of Health of the People's Republic of China. lodine content in edible salt (GB $26878-2011$ ). Beijing: China Criteria Publishing House; 2011.

12. Fisher DA, Oddie TH. Thyroidal radioiodine clearance and thyroid iodine accumulation: Contrast between random daily variation and population data. J Clin Endocrinol Metab. 1969;29:111-5.

13. Fisher DA, Oddie TH. Thyroid iodine content and turnover in euthyroid subjects: Validity of estimation of thyroid iodine accumulation from short-term clearance studies. J Clin Endocrinol Metab. 1969;29:721-7.

14. DeGroot LJ. Kinetic analysis of iodine metabolism. J Clin Endoerinol Metab. 1966;26:149-73.

15. Chinese Nutrition Society. Chinese DRIs handbook. Beijing: China standards press; 2014.

16. Mertz W. Use and misuse of balance studies. J Nutr. 1987;117:1811-3. 
17. Tan L, Tian X, Wang W, et al. Exploration of the appropriate recommended nutrient intake of iodine in healthy Chinese women: an iodine balance experiment. Br J Nutr. 2018;11:1-31.

18. Ministry of Health of the People's Republic of China. Method for determination of iodine in foodstuff by $\mathrm{As}^{3+}-\mathrm{Ce}^{4+}$ catalytic spectrophotometry (WS 302-2008). 2008.

19. National Health Commission of the People's Republic of China. Determination of iodine in urine-part 1 : $\mathrm{As}^{3+}-\mathrm{Ce}^{4+}$ catalytic spectrophotometry (WS/T 107.1-2016). 2016.

20. Andersson $\mathrm{M}$, de Benoist $\mathrm{B}$, Delange $\mathrm{F}$, et al. Prevention and control of iodine deficiency in pregnant and lactating women and in children less than 2-years-old: conclusions and recommendations of the Technical Consultation. Public Health Nutr. 2007;10(12A):1606-11.

21. WHO/UNICEF/ICCIDD. Assessment of iodine deficiency disorders and monitoring their elimination: a guide for programme managers. 3. Geneva: World Health Organization; 2007.

22. Zhang $\mathrm{H}$, Wu M, Yang L, et al. Evaluation of median urinary iodine concentration cut-off for defining iodine deficiency in pregnant women after a long term USI in China. Nutr Metab (Lond). 2019;16:62.

23. Dold S, Zimmermann MB, Baumgartner J, et al. A dose-response crossover iodine balance study to determine iodine requirements in early infancy. Am J Clin Nutr. 2016;104(3):620-8.

24. Malvaux P, Beckers C, De Visscher M. lodine balance studies in nongoitrous children and in adolescents on low iodine intake. J Clin Endocrinol Metab. 1969;29(1):79-84.

25. Harrison MT, Harden RM, Alexander WD, et al. lodine Balance Studies in Patients with Normal and Abnormal Thyroid Function. J Clin Endocrinol Metab. 1965,1077-84.

26. Bakker B, Vulsma T, de Randamie J, et al. A negative iodine balance is found in healthy neonates compared with neonates with thyroid agenesis. J Endocrinol. 1999;161(1):115-20.

27. Vought RL, London WT. lodine intake, excretion and thyroidal accumulation in healthy subjects. J Clin Endocrinol Metab. 1967;27(7):913-9.

28. Riggs DS. Quantitative aspects of iodine metabolism in man. Pharmacol Rev. 1952;4(3):284-370.

29. Lichen Yang J, Wang J, Yang, et al. An iodine balance study to explore the recommended nutrient intake of iodine in Chinese young adults, British Journal of Nutrition, 2020 Jun 22;1-10.

\section{Figures}

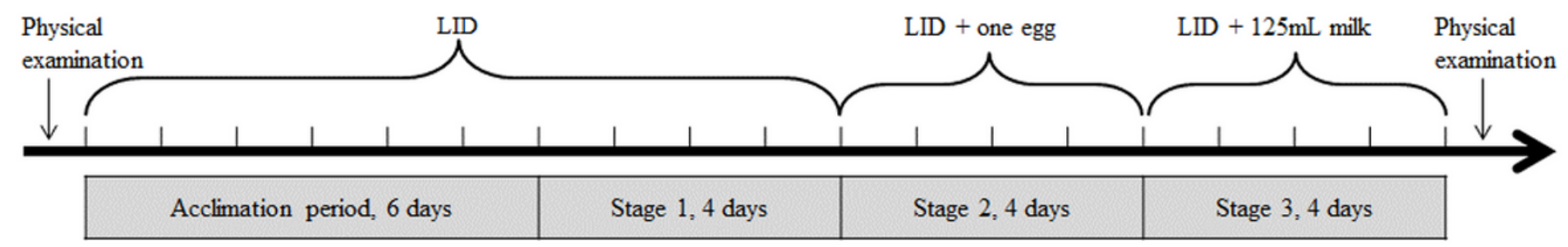

\section{Figure 1}

Study design flow chart for 37 Chinese young adults. 
A

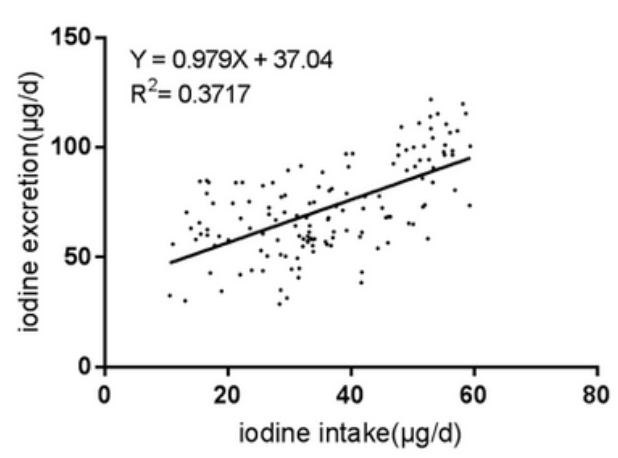

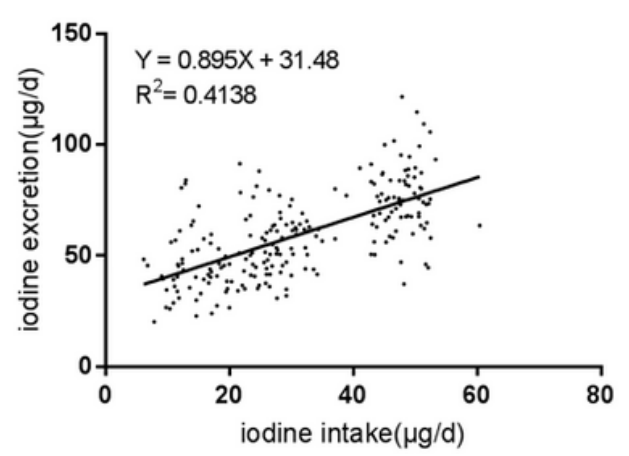

$\mathrm{C}$

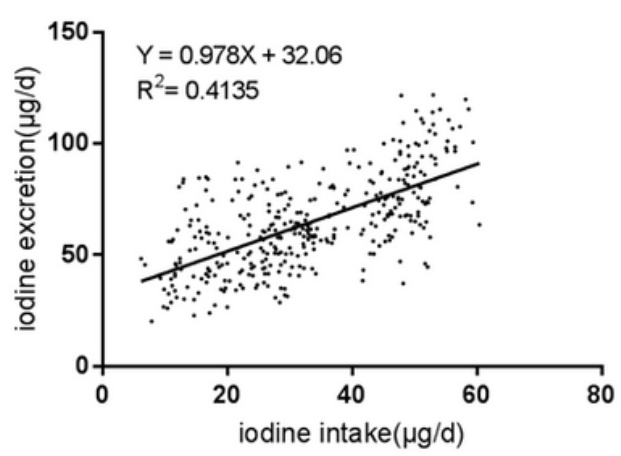

Figure 2

Regression of daily iodine excretion on iodine intake. Each point represent 1 day data of each subject. A: Male, data included 139 samples from 14 young male; B: Female, data included 220 samples from 23 young female; C: Total subjects, data included 359 samples from 37 young adults.

A

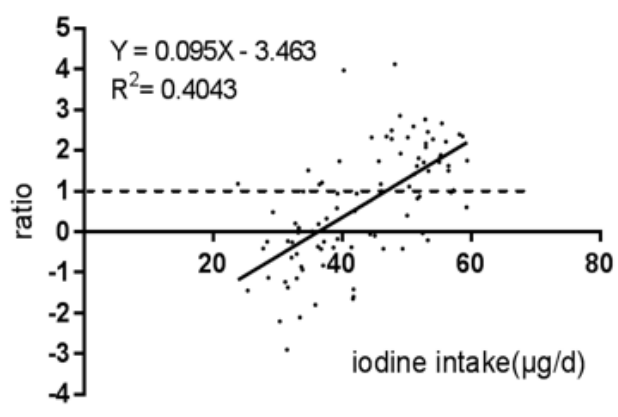

B

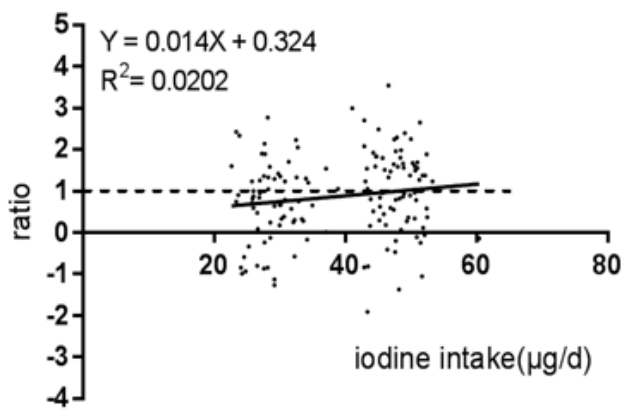

C

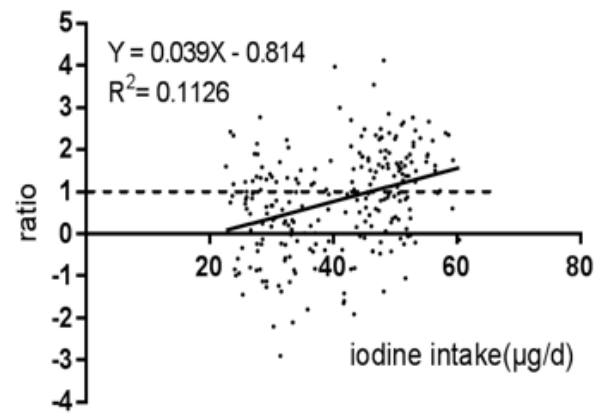

Figure 3

Regression of ratio on iodine intake. ratio $=\triangle$ incrementex $(a) / \triangle$ incrementin(b). (a) $\triangle$ incrementex: iodine excretion increment, (b) $\triangle$ incrementin: iodine intake increment. A: Male, data included 91 samples from 14 young male;B: Female, data included 144 samples from 23 young female; $\mathrm{C}$ : Total subjects, data included 235 samples from 37 young adults.

\section{Supplementary Files}

This is a list of supplementary files associated with this preprint. Click to download.

- Supplemental.docx 